\title{
PERBEDAAN PROBLEM BASED LEARNING DAN DISCOVERY LEARNING TERHADAP PEMAHAMAN SISTEM REPRODUKSI TUMBUHAN DAN HEWAN
}

\author{
Ratu Siti Chodijah ${ }^{1)}$, Muh Rais ${ }^{2}$, Nestiyanto Hadi ${ }^{3)}$ \\ ${ }^{1}$ Prodi Pendidikan Biologi, STKIP Arrahmaniyah Depok \\ Email: chodijah1978@gmail.com \\ ${ }^{23}$ Prodi Pendidikan Biologi, STKIP Arrahmaniyah Depok \\ Email: ntaybio@gmail.com
}

\begin{abstract}
APA Citation: Chodijah, R.S., Rais, M., \& Hadi, N. (2019). Perbedaan Problem Based Learning Dan Discovery Learning Terhadap Pemahaman Sistem Reproduksi Tumbuhan Dan Hewan. Quagga: Jurnal Pendidikan dan Biologi, 11(2), 55-58. doi: 10.25134/quagga.v11i2.1863.
\end{abstract}

Received: 14-07-2019

Accepted: 25-07-2019

Published: 26-07-2019

\begin{abstract}
Abstrak: Penelitian ini bertujuan untuk mengetahui perbedaan pembelajaran PBL dan Discovery Learning terhadap pemahaman siswa pada sistem reproduksi tumbuhan dan hewan. Penelitian dilakukan di SMP.IT Al Fariida dan SMP.IT Luqman Al Hakim Desa Jampang Kecamatan Kemang Kabupaten Bogor. Dalam penelitian ini digunakan metode deskriptif kuantitatif dengan pendekatan studi eksperimendua variabel hasil tes (Y1 dan Y2) dari pemahaman siswa yang belajar dengan model PBL (XI) dan hasil tes dari pemahaman siswa yang belajar dengan model Discovery Learning (X2). Data kedua variabel hasil tes dideskripsikan melalui frekuensi kelas interval data dan nilai-nilai terpusat, yaitu modus (Mo), median (Md), mean (Me) dan nilai simpangan baku (S). Perbedaan pembelajaran PBL dan Discovery Learning diketahui melalui Uji t-perbedaan. Ukuran sampel sebanyak 30 siswa kelas IX SMP.IT Al Fariida dan 30 siswa kelas IX SMP.IT Luqman Al Hakim. Instrumen tes dalam bentuk soal pilihan ganda sebanyak 30 butir soal. Berdasarkan hasil analisis data diperoleh bahwa terdapat perbedaan model pembelajaran PBL dan discovery learning terhadap pemahaman siswa pada sistem reproduksi tumbuhan dan hewan. Dapat disimpulkan bahwa PBL lebih efektif dibandingkan Discovery Learning dengan indikasi meningkatnya motivasi, pengalaman dan pengetahuan serta kemampuan siswa dalam memecahkan permasalahan.
\end{abstract}

Kata kunci : Problem Based Learning (PBL), Discovery Learning, Pemahaman siswa, Instrumen tes.

Abstract: This study aims to determine the differences in PBL and Discovery Learning towards students' understanding of the reproductive systems of plants and animals. The study was conducted at the SMP.IT Al Fariida and SMP .IT Luqman Al Hakim, Jampang Village, Kemang District, Bogor Regency. In this study quantitative descriptive method was used with the experimental study approach two test results variables (YI and Y2) from students 'understanding of learning with PBL models (X1) and test results from students' understanding of the Discovery Learning model (X2). The data of the two test results variables are described through the interval class data and centralized values, namely mode (Mo), median (Md), mean (Me) and standard deviation values (S). The difference between PBL and Discovery Learning is known through $t$ difference test. The sample size was 30 students of class IX SMP.IT Al Fariida and 30 students of class IX SMP.IT Luqman Al Hakim. Test instruments in the form of multiple choice questions were 30 items. Based on the results of data analysis, it was found that there were differences in PBL learning models and discovery learning of students' understanding of the reproductive systems of plants and animals. It can be concluded that $P B L$ is more effective than Discovery Learning with an indication of increasing motivation, experience and knowledge as well as students' ability to solve problems.

Keywords: Problem Based Learning (PBL), Discovery Learning, Student understanding, Test instruments.

\section{PENDAHULUAN}

Kemajuan di bidang Ilmu Pengetahuan dan teknologi (IPTEK) dan globalisasi menuntut tersedianya sumber daya manusia dengan kualitas yang baik. Pendidikan menjadi salah satu faktor terpenting yang dapat menentukan kualitas sumber daya manusia. Suatu negara akan sulit tumbuh dan berkembang menjadi maju tanpa adanya pendidikan. Pendidikan adalah investasi dalam menghadapi persaingan global. Mutu pendidikan yang dihasilkan harus selaras dengan perkembangan IPTEK. Pendidikan harus menghasilkan output yang kompetitif dan komparatif sesuai dengan standar mutu nasional 
dan internasionan untuk menghadapi tantangan global. Selain itu,sumber daya manusia yang dihasilkan juga harus memiliki moral dan budi pekerti yang luhur,tidak hanya menguasai pengetahuan kognitif saja. Proses pendidikan diharapkan mampu menyiapkan generasi muda yang mampu bersaing di masa mendatang.

Terdapat beberapa faktor yang dapat menghasilkan proses pendidikan yang baik. Guru menjadi salah satu faktor yang memiliki peran sangat penting dalam kegiatan pembelajaran. Guru diharapkan memiliki pengetahuan tentang metode mengajar yang baik serta mampu menerapkan dengan efektif dan efisien. Sehingga peserta didik mampu menguasai kompetensikompetensi yang ditentukan dalam pembelajaran yang dilakukan (Kusumaningtias dkk, 2013).

Berbagai literatur model-model pembelajaran, diantaranya adalah model Problem Based Learning, Project Based Learning, Inquiry Learning, Discovery Learning dan Problem Solving. Diantaranya berbagai model tersebut, model Problem Based Learning dan Discovery Learning memiliki potensi yang kuat dalam rangka mendorong siswa untuk mencari tahu dari berbagai sumber melalui observasi, dan bukan hanya diberi tahu oleh para guru.

Pembelajaran berdasarkan masalahmelalui model Problem Based Learning (PBL) dan Discovery Learning mampu mengarahkan siswa untuk berpikir secara sistematis dalam mencari solusi permasalahan yang ditemukan. Siswa diarahkan untuk merefleksikan masalah yang ditemukan selama proses pembelajaran ke dalamkehidupan sehari-hari. Sehingga belajar tidak hanya proses menghafal suatu konsep tetapi juga adanya interaksi dengan lingkungan serta pengalaman yang telah dimilikinya.Pembelajaran dengan model PBL dan Discovery Learning mampu melibatkan siswa untuk belajar menyelesaikan suatu permasalahan dalam kehidupan sehari-hari dan belajar mengenai pengetahuan yang diperlukan. Pembelajaran PBL dapat memandu siswa untuk dapat mengintegrasikan pengetahuan dan keterampilan secara berkelanjutan serta dapat mengaplikasikannya dalam konteks yang relevan (Sani, 2014).

Kemapuan mengevaluasi siswa akan muncul pada tahap analisis dan evaluasi pemecahan masalah, dengan bantuan guru. Siswa memberikan pertimbangan terhadap penyelesaikan suatu masalah yang telah dikemukakan berdasarkan sudut pandangnya sendiri. Selain itu Problem Based Learning melibatkan siswa secara aktif dalam menemukan masalah dan mengutarakan alternatif-alternatif penyelesaian masalah (Purnamaningrum dkk, 2012). Siswa mngembangkan pengetahuan, mengkonstruksi suatu prosedur, dan mengintegrasikan pengetahuan konsep dengan keterampilan yang dimilikinya. Kegiatan di dalam PBL menjadikan siswa semakinterampil dalam menyeleksi informasi yang relevan, untuk selanjutnya dilakukan penganalisisan secara kritis hingga memperoleh hasil yang akurat. Dengan demikian rangkaian kegiatan tersebut dapat meningkatkan pemahaman dan penguasaan konsep siswa.

Berbagai konsep dan kenyataan yang ada, menjadikan peneliti berkeinginan untuk melakukan penelitian yang menjadikan siswa mendapatkan pengalaman untuk memperoleh pemahaman melalui pembelajaran berdasarkan masalah. Dengan harapan siswa generasi berikutnya akan lebih baik pengalaman dan pemahamannya dibandingkan dengan yang terdahulu. Adapun rumusan masalah terkait perbedaan penerapan model pembelajaran Problem Based Learning (PBL) dan Discovery Learning terhadap pemahaman siswa pada materi sistem reproduksi tumbuhan dan hewan.

\section{METODOLOGI PENELITIAN}

Metode penelitian yang digunakan adalah metode deskriptif kuantitatif dengan pendekatan studi eksperimen dua variabel hasil tes (Y1 dan Y2) dari pemahaman siswa yang belajar dengan model PBL (X1) dan hasil tes dari pemahaman siswa yang belajar dengan model Discovery Learning (X2). Data kedua variabel hasil tes dideskripsikan melalui frekuensi kelas interval data dan nilai-nilai terpusat, yaitu modus (Mo), median (Md), mean (Me) dan nilai simpangan baku (S). Perbedaan model pembelajaran PBL dan Discovery Learning dapat diketahui melalui Uji t-perbedaan.

Penelitian ini dilakukan pada siswa kelas IX di dua sekolah wilayah Kecamatan Kemang Kabupaten Bogor, yaitu SMP.IT Al Fariida dan SMP.IT Luqman Al Hakim. Jumlah sampel pada masing-masing sekolah sebanyak 30 siswa. Instrumen tes mengenai pemahaman siswa pada materi sistem reproduksi tumbuhan dan hewan (variabel Y)disusun berdasarkan kisi-kisi dengan jumlah 30 butir soal dalam bentuk pilihan ganda. Selain itu, dilakukan pula observasi yang meliputi kegiatan pemantauan perhatian 
Quagga: Jurnal Pendidikan dan Biologi

Volume 11, Nomor 2, Juli 2019

menggunakan seluruh indera untuk mengetahui penerapan model PBL dan Discovery Learning (Sugiyono, 2013).

\section{HASIL DAN PEMBAHASAN Hasil penelitian}

Tabel 1. Data Pemahaman Siswa

\begin{tabular}{ccc}
\hline Keterangan & Model & Model DL \\
\hline PBL & $13-14$ \\
skekuensi tertinggi & $14-15$ & 13 kelas interval \\
Nilai Modus & 14,41 & 13,04 \\
Nilai Median & 14,23 & 12,50 \\
Nilai Mean & 14,10 & 12,23 \\
\hline
\end{tabular}

Tabel 2. Data Uji Statistik

\begin{tabular}{cc}
\hline Keterangan & Hasil \\
\hline Uji F & 1,14 \\
Uji t & 2,92 \\
F tabel & 1,18 \\
t table & 2,00 \\
\hline
\end{tabular}

Berdasarkan tabel 1, frekuensi kelas interval di atas dapat diketahui bahwa frekuensi tertinggi berada pada kelas interval 14 - 15. Dengan demikian secara garis besar pemahaman siswa menggunakan metode Problem Based Learning (PBL) dalam materi sistem reproduksi pada tumbuhan dan hewan cukup baik. Sedangkan pada metode Discovery Learning frekuensi tertinggi berada pada kelas interval $13-14$.

Berdasarkan tabel 2, Nilai $t$ hitung yang diperoleh lebih besar dari nilai $\mathrm{t}$ tabel $(\mathrm{dk}=$ $(\mathrm{n} 1+\mathrm{n} 2)-2=58)$ dan kesalahan $5 \%$ yaitu 2,00, atau 2,92 > 2,00. Dengan demikian $\mathrm{H}_{0}$ ditolak dan $\mathrm{H}_{1}$ diterima. Jadi dapat disimpulkan : "Terdapat perbedaan pemahaman siswa dalam materi sistem reproduksi pada tumbuhan dan hewan dengan model pembelajaran Problem Based Learning dan model pembelajaran Discovery Learning di kelas IX SMP di Gugus Jampang Kecamatan Kemang Kabuptaen Bogor.

Ada sedikit perbedaan hasil pemahaman siswa antara PBL dan Discovery Learning, namun secara umum hasil keduanya masih masuk kedalam kategori cukup baik. Hal tersebut ditunjang dengan adanya beberapa faktor yang berjalan dengan baik saat pelaksanaan di dalam kelas. Hasil observasi menunjukkan bahwa setiap tahapan yang terdapat dalam rencana pembelajaran dapat dilaksanakan dengan baik. Terdapat komunikasi dua arah antara guru dengan siswa, baik saat siswa kurang memahami materi maupun saat menjawab pertanyaan yang diberikan oleh guru.
p-ISSN 1907-3089, e-ISSN2651-5869

https://journal.uniku.ac.id/index.php/quagga

Adapun hasil deskripsi dan analisis data di atas dapat diketahui bahwa adanya perbedaan pemahaman siswa dalam materi sistem reproduksi pada tumbuhan dan hewan dengan model pembelajaran PBL dan model pembelajaran Discovery Learning yang terlihat pada nilai-nilai modus, median, dan mean dari masing-masing hasil pemahaman siswa di kedua kelas menunjukkan skor pemahaman di kelas model PBL umumnya lebih tinggi dari pada pemahaman di kelas model Discovery Learning. Keadaan diduga berhubungan erat dengan perhatian, rasa ingin tahu dan kemampuan berpikir siswa dalam memecahkan masalah. Sedangkan pada kelas model Discovery Learning siswa memiliki perhatian dan rasa ingin tahu tapi masih belum pada tahap ingin menemukan sesuatu dari materi yang dipelajari, disamping itu jumlah siswa yang cukup banyak menyebabkan kurang efisisen dan membutuhkan waktu yang cukup lama untuk membantu mereka menemukan sesuatu pada materi yang dipelajari, sehingga ketika menjawab soal tes pertimbangannya hanya berdasarkan teori dan bukan pengalaman nyata.

Menurut Ridwan Abdullah Sani 2014, PBL merupakan model pembelajaran yang dilakukan dengan menyajikan permasalahan secara terstruktur, mengajukan beragam variasi pertanyaan yang difasilitasi adanya penyelidikan dan membuka ruang dialog serta diskusi. Permasalahan diselesaikan dengan menerapkan konsep dan prinsip yang secara simultan dipelajari di dalam kurikulum mata pelajaran. Hal tersebut membantu siswa dalam memecahkan masalah dan meningkatkan keterampilan intektual serta rasa tanggung jawab selama proses pembelajaran (Siswanto dkk, 2012).

Model pembelajaran PBL sejalan dengan hakikat pembelajaran IPA yang mempelajari gejala-gejala melalui proses ilmiah yang dibangun atas dasar sikap ilmiah dan hasilnya terwujud menjadi produk ilmiah dengan tiga komponen yaitu konsep, prinsip dan teori (Kusumaningtias dkk, 2013).Model pembelajaran PBL memiliki karakteristik diantaranya siswa harus mempunyai rasa tanggung jawab, simulasi permasalahan yang diterapkan dalam pembelajaran berbasis masalah yang terstruktur dan memungkinkan free inquiry. Selain itu, perlu adanya pengintegrasian dari berbagai disiplin ilmu agar siswa dapat 
Quagga: Jurnal Pendidikan dan Biologi

Volume 11, Nomor 2, Juli 2019

menganalisis permasalahan secara mandiri dan komperhensif (Trianto, 2012).

Analisis akhir mengenai apa yang telah dipelajari dari permasalahan dan diskusi tentang apa konsep dan prinsip-prinsip yang telah dipelajari sangat penting untuk dilakukan. Penilaian diri dan sejawat harus dilakukan pada penyelesaian setiap masalah yang dibahas dan pada akhir setiap unit. Kegiatan yang dilakukan dalam pembelajaran berbasis masalah harus berguna di dunia nyata, ujian siswa harus mengukur kemajuan siswa terhadap tujuan pembelajaran berbasis masalah (Savery, 2006).

Faktor lain yang harus diperhatikan dalam mencapai keberhasilan penerapan model pembelajaran PBL ialah faktor guru. Dalam hal ini, guru berperan untuk membimbing siswa agar dapat menggali dan mengoptimalkan potensi yang dimiliki. Guru memiliki kewajiban untuk dapat mengetahui serta memahami dan terampil dalam proses perencanaan pembelajaran, baik saat merencanakan tujuan dan kompetensi yang akan dicapai maupun juga dalam hal merencanakan proses pembelajarannya (Sanjaya, 2008).

\section{SIMPULAN}

Berdasarkan hasil analisis dapat disimpulkan bahwa model Problem Based Learning (PBL) lebih efektif dibandingkan dengan model Discovery Learning. Model PBL dapat menambah motivasi, pengalaman dan pengetahuan serta kemampuan siswa dalam memecahkan permasalahan. Adapun guna dapat meningkatkan efektifitas penerapan model PBL perlu diperhatikan tata letak (layout) meja dan kursi di dalam kelas yang sebaiknya disusun saling berhadapan. Posisi tersebut memungkinkan setiap anggota kelompok siswa dan antar kelompok siswa dapat melakukan diskusi serta interaksi secara maksimal.

\section{REFERENSI}

Kusumaningtias, A., S. Zubaidah, dan S.E. Indriwati. 2013. Pengaruh Problem Based Learning Dipadu Strategi Numbered Heads Together Terhadap Kemampuan Metakognitif, Berpikir Kritis, dan Kognitif Biologi. Jurnal Penelitian Kependidikan. 23(1): 33-47.

Purnamaningrum, A., S. Dwiastuti, R.M. Probosari dan Noviawati. 2012.
p-ISSN 1907-3089, e-ISSN2651-5869

https://journal.uniku.ac.id/index.php/quagga

Peningkatan Kemampuan Berpikir Kreatif Melalui Problem Based Learning (PBL) pada Pembelajaran Biologi Siswa Kelas X-10 SMAN 3 Surakarta Tahun Pelajaran 2011/2012. Jurnal Pendidikan Biologi. 4(3): 39-51.

Sani, R.A. 2014. Pembelajaran Saintifik untuk Implementasi Kurikulum 2013. Edisi 1. Bumi Aksara. Jakarta.

Sanjaya, W. 2008. Strategi Pembelajaran Berorientasi Standar Proses Pendidikan. Edisi 1. Kencana Prenada Media Group. Jakarta.

Savery, J.R. 2006. Overview of Problem Based Learning, Definitions and Distinctions. Interdisciplinary Journal of Problem Based Learning. 1(1): 9-20.

Siswanto, Maridi dan Marjono. 2012. Pengaruh Model Problem Based Learning (PBL) Terhadap Kemampuan Memecahkan Masalah dan Hasil Belajar Kognitif Biologi Siswa Kelas VII SMP Negeri 14 Surakarta Tahun Pelajaran 2011/2012. Jurnal Pendidikan Biologi. 4(2): 53-59.

Sugiyono. 2013. Metode Penelitian Pendekatan Kuantitatif, Kualitatif dan $R \& D$. Edisi 1. Alfabeta. Bandung.

Trianto. 2012. Model Pembelajaran Terpadu: Konsep, Strategi dan Implementasinya dalam Kurikulum Tingkat Satuan Pendidikan (KTSP). Edisi 1. Bumi Aksara. Jakarta. 